DOI: 10.20472/IAC.2018.935.002

\author{
AMINA ABDULLAH \\ Saint Leo University, United States \\ CRAIG WINSTEAD \\ Saint Leo University, United States \\ TAMIKA LETT \\ Saint Leo University, United States
}

\title{
AN APPLIED MODEL TO ENHANCE THE CLASSROOM THROUGH INTERDISCIPLINARY ACTIVITY
}

\begin{abstract}
:
This article provides details on how learning can happen outside of the classroom. The authors provide information on taking an interdisciplinary approach to teaching in various settings outside of the classroom. Through discussion and practical examples, they share how such activities not only enhance student knowledge but also provide students with the opportunity to ask questions, engage in discussion, and practice what they are learning as well as reinforces reading and in-class discussion. The areas of examination include community service, active learning, and service learning. The first example explores having students volunteer at a community feeding event. The second example reviews how students work together at an escape room. The third and final example explores how students interact with one another and workers during visits with community partners. What emerges are additional modalities to enhance learning.
\end{abstract}

\section{Keywords:}

community service, active learning, service learning 